\title{
PENGGUNAAN METODE QULITY FUCTION DEPLOYEMENT DALAM MENENTUKAN KARAKTERISTIK KEBUTUHAN PENGGUNA ALAT PEMOTONG SINGKONG
}

\author{
Siti Lestariningsih \\ Fakultas Teknik, Program Studi Teknik Industri \\ Universitas Widya Mataram \\ Email: Sitilestariningsih@yahoo.com \\ Iva Mindhayani \\ Program Studi Teknik Industri \\ Universitas Widya Mataram \\ Email: ivamindhayani@gmail.com
}

\begin{abstract}
ABSTRAK
Penelitian ini bertujuan untuk mengetahui karakteristik-karakteristik kebutuhan pengguna yang perlu diperhatikan dalam membuat alat pemotong singkong baru berdasarkan metode Quality Fuction Deployement $(Q F D)$.Terdapat 11 karakteristik kebutuhan pengguna alat pemotong singkong dengan engkol kaki. Setelah dilakukan analisis dan evaluasi kebutuhan pengguna (voice of customer) terhadap alat pemotong singkong saat ini, ada 10 karakteristik kebutuhan pengguna yaitu mudah dibersihkan, mudah dalam pengoperasian, perawatan mudah, harga alat terjangkau, kecepatan pemotongan, dapat dipakai oleh siapapun, masa pakai lama, tekstur hasil pemotongan, kesesuaian alat dengan kondisi kerja, desain alat ergonomis. Hasil penelitian menunjukkan karakteristik teknik yang perlu diperhatikan dalam melakukan perbaikan alat pemotong singkong dengan engkol kaki secara berurutan yaitu ukuran sesuai antropometri, kualitas bahan, alat potong, posisi alat potong, ketinggian meja dan kursi, posisi pedal. Agar keinginan dan kebutuhan pengguna dapat terpenuhi dalam perancangan alat potong singkong dengan pedal kaki disarankan sesuai dengan penentuan target dalam pembahasan.
\end{abstract}

Kata kunci: $Q F D$; kebutuhan pengguna; alat pemotong singkong.

\begin{abstract}
Aim this research is knowing caracteristic of customer need to be considered in making new cutter equipment of cassava based on the Quality Fuction Deployement (QFD) method. There are 11 characteristics of the needs of cutter equipment of cassava with foot cranks. After analyzing and evaluating user needs (voice of customers) of cutter equipment of cassava this time, there are 10 characteristics of user needs, namely easy to clean, easy to operate, easy maintenance, affordable equipment prices, cutting speed, can be used by anyone, long life, cutting texture, equipment suitability with working conditions, equipment design ergonomic. The results showed the technical characteristics that need to be considered in repairing cutter equipment of cassava with foot cranks in sequence, namely the size according to anthropometry, the quality of the material, cutting equipment, the position of the cutting equipment, the height of the table and chair, position of the pedals. In order for the desires and needs of users to be fulfilled in the design of cutter equipment of cassava with foot pedals is recommended according to the determination of targets in the discussion.
\end{abstract}

Keywords: QFD; customer need; cutter equipment of cassava.

\section{PENDAHULUAN}

Industri rumah tangga salah satunya industri keripik singkong masih bertahan sampai saat ini. Kripik singkong merupakan makanan ringan yang disukai semua kalangan, mulai dari anak kecil sampai orang tua. Untuk bisa menghasilkan keripik singkong dengan ketebalan yang seragam dibutuhkan alat pemotong singkong yang bisa digunakan untuk memotong dengan ketebalan yang sama sesuai keinginan.

Alat yang digunakan untuk memotong singkong rata-rata masih sederhana, kurang produktif dan tidak ergonomis. Alat yang tidak ergonomis tentunya dapat mengganggu keberlangsungan dalam bekerja. Di satu sisi pekerja menjadi tidak optimal dalam bekerja karena mereka merasakan sakit dan nyeri di beberapa anggota tubuh, disisi lain perusahaan juga rugi karena efektivitas, efisiensi dan produktivitas pekerja turun[6]. Awalnya alat yang ada dan digunakan untu memotong singkong dengan cara sederhana yaitu 
menggunakan sitem engkol tangan. Hal ini mendorong dilakukan suatu penelitian tentang alat potong singkong baru dengan sistem kayuh menggunakan kaki, namun hasilnya masih belum sesuai kebutuhan. Untuk itu perlu dirancang dan dikembangkan alat pemotong keripik singkong yang ergonomis serta sesuai dengan yang diinginkan oleh pengusaha keripik singkong.

Dari hasil pengamatan awal terhadap alat pemotong singkong sistem kayuh atau alat pemotong dengan engkol kaki, alat ini baru dipakai operator laki-laki, padahal karryawannya tidak hanya laki-laki saja sehingga keinginan pengusaha kripik singkong (voice of customer) belum bisa terpenuhi.

Berdasarkan latar belakang masalah tersebut perlu dilakukan evaluasi terhadap alat pemotong singkong sistem kayuh atau alat potong dengan engkol kaki, untuk itu dilakukan penelitian yang bertujuan mengetahui karakteristik-karakteristik kebutuhan pengguna yang perlu diperhatikan dalam membuat alat pemotong singkong baru berdasarkan metode House of Quality (HOQ). Dimana HOQ merupakan matriks pertama dalam metode QFD yang berisi informasi mengenai kebutuhan dan keperluan pelanggan[2]. QFD merupakan suatu alat yang digunakan untuk mengidentifiaksi karakteristik utama pada kualitas performansi dan mengukur pengaruh faktor pada kualitas performansi[4].

Penelitian terkait perancangan ataupun pembuatan alat pemotong singkong sudah dilakukan beberapa peneliti. Setiono, D.A (2008) dalam penelitiannya merancang bangun alat pengiris singkong otomatis berbasis mikrokontroler AT89S51. Alat pengiris singkong tersebut dilengkapi perangkat lunak menggunakan pemrograman assembly read 51 dan telah disetting dengan 3 pilihan ketebalan yang berbedabeda. NN (2011) membuat alat pemotong ubi kayu bentuk cassava fries. Penelitian ini menghasilkan alat yang dapat dipakai untuk memotong ubi kayu dengan besarnya kerusakan hasil 3,4\%, besarnya hasil terpotong yang keluar $96,6 \%$, kapasitas alat $23,96 \mathrm{~kg} / \mathrm{jam}$, nilai efisiensi pemotongan $60,98 \%$, dan biaya pokok alat Rp. 311.32/kg. Dalam Kus Pranata A. (2015) membuat alat pemotong singkong dengan engkol kaki. Hasil penelitiannya berhasil mengurangi waktu siklus pemotongan singkong sebanyak 25 detik, serta mengurangi rasa sakit keluhan pada pekerja/operator.

Susandari, dkk (TT) dalam penelitiannya menggabungkan metode Rekayasa kansei dan QFD, karena gabungan metode tersebut dapat menangkap dan menterjemahkan keinginan konsumen. Dan akan menghasilkan produk yang unik dan lebih bersahabat. Objek penelitian terhadap interior komuter Arek Surokerto, dengan pengembangan matriks QFD pada pembagian kolom Voice of Costumer (VOC) terdiri dari wanita, laki-laki dan lanjut usia. Berdasarkan matriks QFD ditunjukan bahwa preferensi desain antara laki-laki dan perempuan hampir sama, bedanya pada sistem pemisahan gender wanita menginginkan gerbong terpisah namun laki-laki menghendaki pemisahan masih dalam satu gerbong[9].

\section{METODOLOGI PENELITIAN}

Langkah awal dalam penelitian ini adalah dengan melakukan observasi terhadap alat pemotong singkong yang ada di laboratorium sistem produksi Universitas Widya Mataram Yogyakarta. Observasi bertujuan untuk mengetahui permasalahan yang ada. Hasil observasi awal diketahui bahwa alat pemotong singkong yang ada di Lab. Sistem Produksi tidak ergonomis. Selanjutnya dilakukan penyebaran kuisioner terhadap responden yang berjumlah 30 responden yang sebelumnya sudah mencoba alat pemotong singkong yang ada. Pembuatan kuesioner berdasarkan karakteristik kebutuhan pengguna alat pemotong singkong tersebut yang akan dipakai dalam penentukan kepuasan dan kepentingan konsumen. Hasil tabulasi kuisioner selanjutnya di olah dengan menggunakan SPSS 16 untuk dilakukan uji validitas dan reliabilitas serta uji kecukupan data. Langkah selanjutnya adalah membuat rumah kualitas (HOQ) berdasarkan karakteristik kebutuhan pengguna, yaitu: Melakukan identifikasi semua kebutuhan dan keinginan konsumen terhadap produk; Mengidentifikasikan tingkat kepentingan konsumen untuk masingmasing karakteristik konsumen yang telah ada; Menerjemahkan seluruh kebutuhan dan keinginan konsumen (Whats) ke dalam karakteristik desain (Hows); Menentukan hubungan yang terjadi antara masing-masing karakteristik konsumen dengan karakteristik desain; Menentukan target perusahaan terhadap masing-masing karakteristk desain yang ada; Membentuk matrik korelasi yang menunjukkan hubungan antar masing-masing karakteristik desain yang ada; Dengan menetapkan nilai-nilai yang berupa angka pada matriks hubungan keinginan konsumen dan karakteristik desain maka seluruh penilaian dapat disusun berdasarkan kepentingan relatif dari setiap kebutuhan dan keinginan konsumen. Tahapan penelitian bisa dilihat pada Gambar 1. 


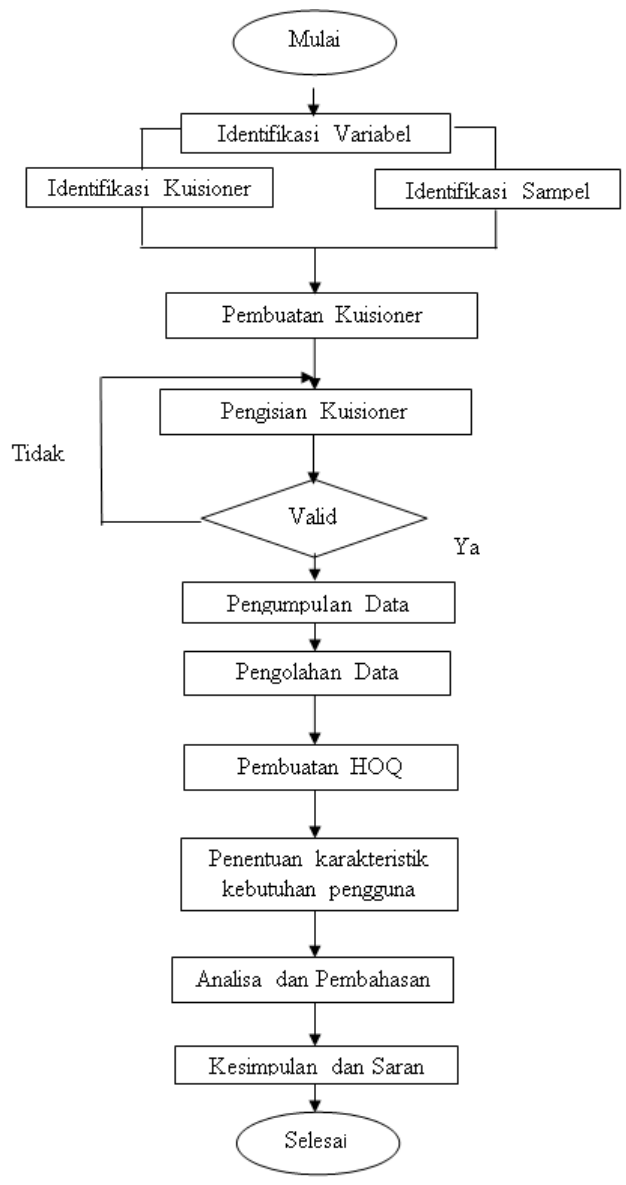

Gambar 1. Tahapan Penelitian

\section{HASIL DAN PEMBAHASAN}

Hasil penyebaran kuesioner uji coba alat pemotong singkong yang ada, tanggapan pengguna terhadap alat pemotong singkong dapat dilihat pada Tabel 1 .

Tabel 1. Tanggapan pengguna terhadap alat pemotong singkong

\begin{tabular}{|c|c|c|c|c|}
\hline No & Atribut & Keterangan & Jumlah & Prosentase (\%) \\
\hline \multirow[t]{3}{*}{1} & Kemudahan pengoperasian & Sangat mudah & 13 & 43,3 \\
\hline & & Mudah & 17 & 56,7 \\
\hline & & Tidak Mudah & 0 & 0 \\
\hline \multirow[t]{3}{*}{2} & Ukuran ketinggian tempat duduk & Sangat sesuai & 4 & 13,3 \\
\hline & & Sesuai & 8 & 26,7 \\
\hline & & Tidak sesuai & 18 & 60 \\
\hline & Jarak jangkauan alat dengan tangan & & & \\
\hline \multirow{3}{*}{3} & operator & Sangat sesuai & 5 & 16,7 \\
\hline & & Sesuai & 19 & 63,3 \\
\hline & & Tidak sesuai & 6 & 20 \\
\hline \multirow[t]{3}{*}{4} & Jarak pedal / letak pedal & Sangat sesuai & 4 & 13,3 \\
\hline & & Sesuai & 13 & 43,3 \\
\hline & & Tidak sesuai & 13 & 43,3 \\
\hline \multirow[t]{3}{*}{5} & Proses mengayuh pedal & Berat & 3 & 10 \\
\hline & & Sedang & 13 & 43,3 \\
\hline & & Ringan & 14 & 46,7 \\
\hline \multirow[t]{3}{*}{6} & Kesesuaian hasil pemotongan & Banyak tekanan & 0 & 0 \\
\hline & & Sedikit tekanan & 25 & 83,3 \\
\hline & & Tidak perlu & 5 & 16,7 \\
\hline \multirow[t]{2}{*}{7} & Kesesuaian kecepatan potong & Sangat sesuai & 0 & 0 \\
\hline & & sesuai & 21 & 70 \\
\hline
\end{tabular}




\begin{tabular}{|c|c|c|c|c|}
\hline No & Atribut & Keterangan & Jumlah & Prosentase (\%) \\
\hline \multirow{5}{*}{8} & \multirow{5}{*}{ Perasaan saat penggunaan } & Tidak sesuai & 9 & 30 \\
\hline & & Merasa nyaman & 4 & 13,3 \\
\hline & & Biasa saja & 18 & 60 \\
\hline & & Tidak nyaman & 8 & 26,7 \\
\hline & & Sakit & 0 & 0 \\
\hline \multirow[t]{2}{*}{9} & \multirow[t]{2}{*}{$\begin{array}{l}\text { Pada saat alat digunakan tubuh } \\
\text { merasa sakit }\end{array}$} & Sedikit sakit & 19 & 63,3 \\
\hline & & Tidak sakit & 11 & 36,7 \\
\hline \multirow[t]{3}{*}{10} & \multirow[t]{3}{*}{ Bagian tubuh yang sakit } & Kaki & 8 & 26,7 \\
\hline & & Tangan & 10 & 33,3 \\
\hline & & Pinggang & 12 & 40 \\
\hline \multirow[t]{3}{*}{11} & \multirow[t]{3}{*}{ Kemudahan perawatan alat } & Sangat mudah & 4 & 13,3 \\
\hline & & Mudah & 24 & 80 \\
\hline & & Tidak mudah & 2 & 6,7 \\
\hline \multirow[t]{3}{*}{12} & \multirow[t]{3}{*}{ Harga ekonomis } & Sangat murah & 0 & 0 \\
\hline & & Murah & 17 & 56,7 \\
\hline & & Tidak murah & 13 & 43,3 \\
\hline \multirow[t]{3}{*}{13} & \multirow[t]{3}{*}{ Kemudahan dalam pembersihan } & Sangat mudah & 5 & 16,7 \\
\hline & & Mudah & 25 & 83,3 \\
\hline & & Tidak mudah & 0 & 0 \\
\hline \multirow[t]{3}{*}{14} & $\begin{array}{l}\text { Perbandingan proses dengan alat } \\
\text { potong manual }\end{array}$ & Lebih lambat & 0 & 0 \\
\hline & & Cepat & 6 & 20 \\
\hline & & Lebih cepat & 24 & 80 \\
\hline
\end{tabular}

Berdasarkan Tabel 1. Tanggapan Pengguna Alat Pemotong Singkong diketahui bahwa respon dari responden sebagai berikut:

a. Kemudahan pengoperasian

43,3\% responden menjawab alat pemotong singkong sistem kayuh sangat mudah dioperasikan, sedangkan responden yang menjawab mudah dalam pengoperasian sebanyak $56 \%$.

b. Ukuran ketinggian tempat duduk

Sebanyak $13,3 \%$ responden menjawab sangat sesuai, sebanyak $26,7 \%$ responden menjawab sesuai dan $60 \%$ responden menjawab ukuran tempat duduk tidak sesuai. Awalnya alat pemotong singkong sistem kayuh hanya diperuntukkan untuk operator laki-laki saja, sehingga ketinggian kursi yang dipergunakan disesuaikan dengan postur operator laki-laki. Sedangkan konsumen / pengguna ingin supaya alat bisa dioperasikan oleh wanita. Sehingga dari hasil uji terhadap responden wanita ketinggian kursi tidak sesuai dengan postur wanita.

c. Jarak jangkauan alat dengan tangan operator

Sebanyak $16,6 \%$ responden menjawab sangat sesuai, sebanyak $63,3 \%$ responde menjawab sesuai dan $20 \%$ responden menjawab tisak sesuai.

d. Jarak pedal / letak pedal

Sebanyak Sebanyak 13,3\% responden menjawab sangat sesuai, sebanyak 43,3\% menjawab sesuai dan 43,3\% menjawab tidak sesuai. Banyak responden yang menjawab tidak sesuai hal tersebut dikarenakan postur tubuh wanita lebih kecil dari laki-laki sehingga jangkauan kaki ke pedal tentunya berbeda juga.

e. Proses mengayuh pedal Sebanyak $10 \%$ responden menjawab berat, $43,3 \%$ responden menjawab sedang dan sebanyak 46,7 responden menjawab ringan.

f. Kesesuaian hasil pemotongan

$83,3 \%$ responden menjawab perlu sedikit tekanan, $16,7 \%$ menjawab tidak perlu tekanan dan tidak ada yang menjawab banyak tekanan. Untuk mendapatkan hasil pemotongan singkong yang sesuai dan seragam berdasarkan hasil percobaan alat responden merasa membutuhkan tenaga untuk menekan.

g. Kesesuaian kecepatan potong $70 \%$ responden menjawab sesuai, sedangkan $30 \%$ menjawab tidak sesuai.

h. Perasaan saat penggunaan $13,3 \%$ responden merasa nyaman menggunakan alat pemotong singkong, $60 \%$ menjawab biasa saja dan 26,7\% menjawab tidak nyaman.

i. Pada saat alat digunakan tubuh merasa sakit 
63,3\% menjawab sedikit sakit, 36,7\% menjawab tidak sakit dan $0 \%$ menjawab sakit.

j. Bagian tubuh yang sakit

26,7\% responden menjawab bagian kaki sakit, 33,3\% responden menjawab bagian tangan measa sakit dan $40 \%$ menjawab bagian pinggang terasa sakit. Hal ini terjadi karena ketinggian kursi terhadap alat pemotong tidak sesuai sehingga menyebabkan responden banyak merasakan sakit dibagian pinggang.

k. Kemudahan perawatan alat $13,3 \%$ responden menjawab sangat mudah dalam perawatan, $80 \%$ responden menjawab mudah dalam perawatan dan $6,7 \%$ responden menjawab tidak mudah dalam perawatan.

1. Harga ekonomis $56,7 \%$ resnpoden menjawab harga alat murah dan sebanyak 43,3\% menjawab harga alat tidak murah dan responden tidak ada yang menjawab harga alat murah.

m. Kemudahan dalam pembersihan

$16,7 \%$ responden menjawab sangat mudah, $83,3 \%$ responden menjawab mudah dibersihkan.

n. Perbandingan proses dengan alat potong manual

Semua responden tidak mengetahui perbandingan alat pemotong singkong sistem kayuh dengan alat potong manual.

Sedangkan perhitungan rata-rata tingkat kepuasan dan tingkat kepentingan hasil dari kuesioner II sesuai dengan Tabel 2.

Tabel 2. Rata-rata tingkat kepuasan dan tingkat kepentingan responden

\begin{tabular}{llcc}
\hline No & Atribut & $\begin{array}{c}\text { Tingkat } \\
\text { Kepuasan }\end{array}$ & $\begin{array}{c}\text { Tingkat } \\
\text { Kepentingan }\end{array}$ \\
\hline 1 & Mudah dalam pengoperasian (A) & 3,50 & 4,10 \\
2 & Kecepatan Potong (B) & 3,80 & 4,00 \\
3 & Ketebalan Pemotongan (C) & 3,67 & 3,47 \\
4 & Tekstur hasil pemotongan (D) & 2,97 & 3,63 \\
5 & Harga Alat terjangkau (E) & 2,67 & 3,53 \\
6 & Dapat dipakai oleh siapapun (F) & 3,67 & 4,00 \\
7 & Mudah dibersihkan (G) & 3,53 & 4,07 \\
8 & Perawatan mudah (H) & 3,27 & 4,13 \\
9 & Kesesuaian alat dengan kondisi kerja (I) & 2,90 & 4,03 \\
10 & Desain alat ergonomis (J) & 2,53 & 3,97 \\
11 & Masa pakai lama (K) & 3,70 & 4,37 \\
\hline
\end{tabular}

Berdasarkan Tabel 2. dalam penentuan karakteristik kebutuhan pengguna dari ke 11 atribut dengan besarnya nilai rata-rata tingkat kepuasan dan tingkat kepentingan, maka atribut yang dipakai dalam pembuatan HOQ yaitu atribut yang mempunyai nilai rata-rata tingkat kepentingannya diatas 3,5 berjumlah 10 item yaitu : 1) mudah dalam pengoperasian, 2) Kecepatan potong, 3) Tekstur hasil pemotongan, 4) harga alat terjangkau, 5) dapat dipakai oleh siapapun, 6) mudah dibersihkan, 7) perawatan mudah, 8) kesesuaian alat dengan kondisi kerja, 9) desain alat ergonomis, 10) masa pakai lama.

Tahapan selanjutnya adalah menyusun House of Quality (HOQ) dalam metode Quality Function Development (QFD). Teknik HOQ memberikan prioritas tergantung pada tingkat kesulitan parameter teknik, target nilai, bobot mutlak, dan bobot relatif [3]. Dalam menyusun HOQ terdapat langkah-langkah yang butuh diperhatikan yaitu:

a. Penentuan tingkat kepentingan absolut dan kepentingan relatif

b. Menentukan Goal (Target)

Penentuan Goal ini berkaitan dengan kepuasan pengguna terhadap Alat Pemotong Keripik Singkong sistem kayuh atau dengen engkol kaki bahwa tingkat perbaikan yang akan dilakukan oleh tim pengembang untuk memenuhi tuntutan dari pengguna dan juga merupakan target performance dari masing-masing indikator kebutuhan pengguna sehingga memberikan Competitive Advantage atau keuntungan yang kompetitif tim pengembang serta pengguna sesuai

c. Rasio pengembangan (Improvement Ratio)

Rasio ini memberikan bobot dari kebutuhan pelanggan yang akan membutuhkan pengembangan yang paling banyak. Rasio pengembangan merupakan perbandingan goal dan customer satisfication performance. Perhitungan rasio pengembangan (improvement ratio) menggunakan persamaan 1.

Improvement Ratio $=\frac{\text { Goal }}{\text { Customer Satisfaction Performance }}$ 
d. Penentuan Sales Point

Sales point ditetapkan oleh tim pengembang adapun besarnya nilai akan mencerminkan besarnya tingkat kepentingan. Hal ini bisa diperoleh bila dilakukan peningkatan perbaikan dan penyempurnaan indikator yang ada.

Besarnya nilai sales point yang umum digunakan adalah[1]
1 : tanpa titik penjualan
1,2 : titik penjualan menengah
1,5 : titik penjualan ketat (kuat)

e. Menentukan Bobot Kepentingan (Row Weight)

Raw Weight diperoleh dari rumus sebagai berikut[1]

Raw Weigth $=($ Importance to Customer $) \times($ Improvement Ratio $) \times($ Sales Point $)$

f. Mencari Bobot Kepentingan normal Normalized Weight

g. Menentukan Respon Teknis (Technical Respons)

h. Penentuan Matriks Korelasi Teknis

i. Mencari Nilai Kepentingan Teknis

Nilai kepentingan teknis digunakan untuk mengetahui nilai kebutuhan atau kepentingan teknis masing-masing atribut sehingga dapat diketahui atribut mana yang mempunyai nilai kepentingan teknis tertinggi ataupun yang terendah. Terdapat dua macam nilai kepentingan teknis yaitu nilai kepentingan teknis absolut (Absolute Importance) dan nilai kepentingan relatif (Relative Importance). Berdasarkan hasil perhitungan urutan prioritas sebagai berikut : 1) ukuran sesuai antropometri, 2) kualitas bahan, 3) alat potong, 4) posisi alat potong, 5) ketinggian meja dan kursi, 6) posisi pedal.

j. Hubungan Teknis

Hasil pengolahan data dipakai sebagai dasar pembuatan HOQ. Penggunaan QFD didalam pembuatan rumah kualitas sesuai Gambar 2.

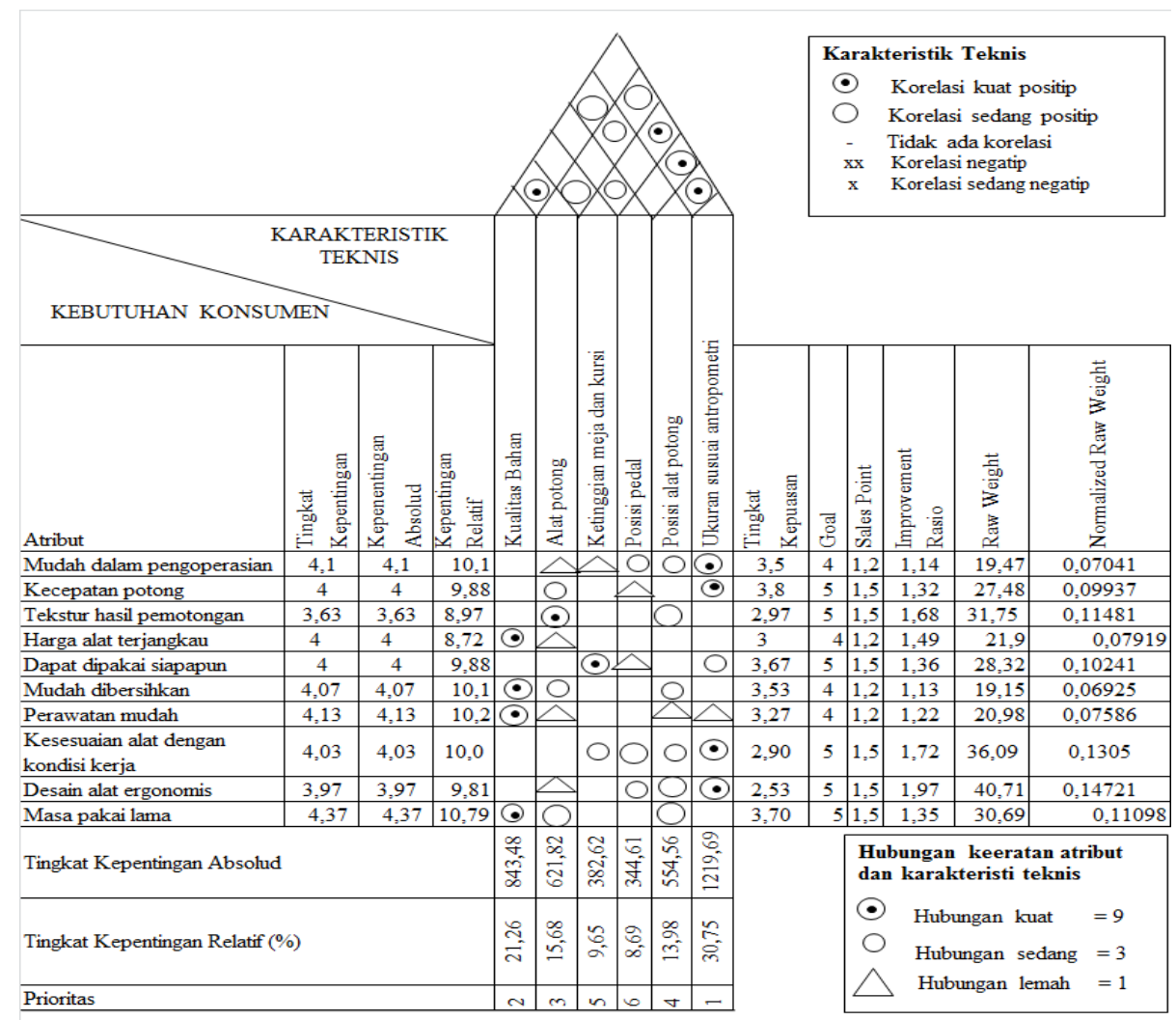

Gambar 2. House Of Quality (HOQ) Berdasarkan Kebutuhan Pengguna

Penentuan target dilakukan setelah penyusunan HOQ. Dalam penentuan target ini diperlukan informasi mengenai keinginan dan kebutuhan pengguna alat potong singkong, kebutuhan teknis dari alat tersebut, serta evaluasi pembanding, maka dapat diperoleh ketentuan-ketentuan yang ingin dicapai dalam perancangan alat potong singkong sistem kayuh atau alat potong singkong dengan pedal kaki adalah : 
a. Ukuran sesuai antropometri, dimensi dari alat tersebut harus disesuai dengan ukuran ketinggian, ukuran jangkauan tangan, ukuran panjang kaki dari pengguna agar para pengguna alat tersebut merasa nyaman.

b. Kualitas bahan alat potong tersebut terdiri dari tiga komponen yaitu kerangka, penggerak dan pemotong

c. Alat potong terdiri dari landasan potong, rumah pisau, piasu dan Bearing.

d. Posisi alat potong untuk memudahkan penggunaan alat maka letak dari mata pisau harus berada dalam rumah pisau namun pada alat tersebut belum ada penutupnya.

e. Ketinggian meja dan kursi penentuan tinggi rangka meja dan kursi alat pemotong singkong dengan mekanisme kayuh sepeda dapat dijelaskan, sebagai berikut:

Tinggi rangka meja = Tinggi Popliteal $(\mathrm{TP})$ persentil-95+Tinggi siku duduk (TSD) persentil-95= $49,23+30,30=79,53 \mathrm{~cm}$

Tinggi Tempat Duduk menggunakan tinggi tempat duduk persentil-5 diharapkan orang yang mempunyai kaki pendek bisa duduk dengan mudah $=$ Tinggi Popliteal $(\mathrm{TP})$ persentil-5= 43,17 cm.[4]

f. Posisi pedal jarak pedal dengan tempat duduk menggunakan panjang dan tinggi popliteal persentil5 diharapkan orang yang mempunyai kaki pendek bisa mengayuh sepeda dengan mudah. Pedal berada diposisi tengah telapak kaki pada waktu mengayuh. Sudut panjang kaki dengan telapak kaki sebesar 90 derajat. Sudut pedal dengan rangka penopang sebesar 45 derajat. Alat pemotong singkong yang dianalisis seperti pada Gambar 3.

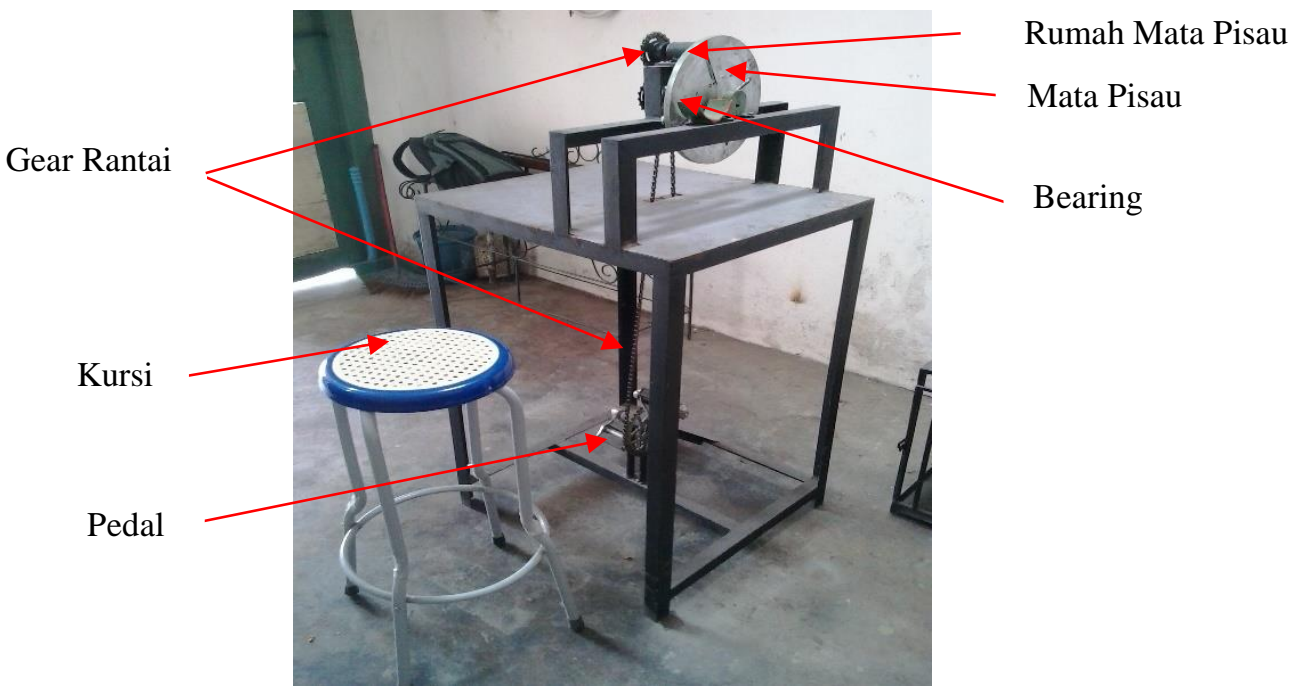

Gambar 3. Satu Set Alat Pemotong Singkong

\section{KESIMPULAN DAN SARAN}

\subsection{Kesimpulan}

Dari hasil penelitian dan pembahasan dapat disimpulkan bahwa:

a. Terdapat 11 karaketeristik kebutuhan pengguna alat pemotong singkong dengan engkol kaki.

b. Terdapat 10 karakteristik kebutuhan pengguna yang terdiri dari a) mudah dibersihkan, b) mudah dalam pengoperasian, c) perawatan mudah, d) harga alat terjangkau, e) kecepatan pemotongan, f) dapat dipakai oleh siapapun, g) masa pakai lama, h) tekstur hasil pemotongan, i) kesesuaian alat dengan kondisi kerja, j) desain alat ergonomis. Karakteristik teknik yang perlu diperhatikan dalam melakukan perbaikan alat pemotong singkong dengan engkol kaki secara berurutan adalah a) ukuran sesuai antropometri, b) kualitas bahan, c) alat potong, d) posisi alat potong, e) ketinggian meja dan kursi, f) posisi pedal.

\subsection{Saran}

Selain perbaikan dari karakteristik teknik tersebut disarankan dalam pembuatan alat, perlu ditambahakan penutup rumah pisau pada alat tersebut agar hasil potongan dapat terkumpul pada tempatnya (tidak berserakan). Dalam perancangan alat potong singkong sistem kayuh atau alat potong singkong 
dengan pedal kaki sesuai dengan poin sebelas dalam pembahasan yaitu menentukan target, hal ini dilakukan agar keinginan dan kebutuhan pengguna dapat terpenuhi.

\section{DAFTAR PUSTAKA}

[1] Cohen, Lou. 1995. Quality Function Deployment : How To Make QFD Work For You. Massachuset : Addison-Wesley Publishing Company.

[2[ Gargion, L.A. 1999. "Using Quality Function Deployment (QFD) In The Design Phase of an Appartement Construction Project”. Proceeding IGLC-7, University of California, Berkeley, CA, USA. 26-17 July.

[3] Hamza, R.M.A. 2011. "Enhancing Quality of Vocational Training Outcome to Satisfy the Labor Market Demands in Kuwait by Using Quality Function Deployment Method (QFD)". Journal of Industrial Engineering and Management. 4(2), 387-402.

[4] Kus Pranata, A. 2015. Redisign Alat Perajang Kripik Singkong Berdasarkan Data Antropometri Pada Pembuatan Kripik Singkong. Sekripsi Tidak diterbitkan. Jurusan Teknik Industri Universitas Widya Mataram Yogyakarta.

[5] Liu, Y., and Xu, J. TT. "QQFD Model For Quality Performance Self Assessment". The Asian Journal on Quality. Vol 7. No.1

[6] Mindhayani, I dan Purnomo, H. 2016. "Perbaikan Sistem Kerja Untuk Meningkatkan Produktivitas Karyawan”. Jurnal PASTI. X(1), 98-107.

[7] NN. 2011. Rancang Bangun Dan Uji Teknis Alat Pemotong Ubi Kayu Bentuk Cassava Fries. Skripsi. Program Studi Teknik Pertanian Fakultas Teknologi Pertanian Universitas Andalas.

[8] Setiono, D. A. 2008. Rancang Bangun Sistem Pengiris Singkong Otomatis Berbasis Mikrokontroler AT89S51. Tugas Akhir. Program Studi DIII Instrumentasi dan Elektronika Jurusan Fisika FMIPA Universitas Diponegoro.

[9] Susandari, H, dkk. TT. "Pengembangan Metode QFD Multi Gunna Untuk Merancang Transportasi Massal Berbasis Gender”. Artikel Jurusan Teknik Industri, Institut Teknologi Sepuluh Nopember (ITS), Surabya. 